\title{
ART
}

\section{PHENOMENON OF THE BIEDERMEIER PIANO MUSIC IN XIX CENTURY}

\author{
Nataliia Chuprina \\ Ph. D in History of Arts, \\ Acting Associate Professor of the Department of General and specialized piano \\ Odessa National A.V. Nezhdanova Academy
}

DOI: https://doi.org/10.31435/rsglobal_sr/30112019/6814

\section{ARTICLE INFO}

Received 21 September 2019

Accepted 15 November 2019

Published 30 November 2019

\section{KEYWORDS}

Biedermeier, pre-Biedermeier, post-Biedermeier, Romanticism, Restoration.

\begin{abstract}
The aim of the article - to consider the Biedermeier as a phenomenon of European culture, generated by the Restoration era. The evolutionary and typological qualities of Biedermeier in all the diversity of its national models (German, Polish, Russian, Italian, French) are projected on the piano music of XIX century and its performing traditions; to present Biedermeier as a specific direction of musical art which creates the conditions for understanding and absorbing of a complex academic repertoire by an unprepared audience.

Methodology of the article - historical, general philosophical, social analysis of the Biedermeier as a cultural phenomenon, comparative analysis of national characteristics of the Biedermeier display.

Scientific novelty - the Biedermeier phenomenon is presented as a specific direction of musical art which creates the conditions for understanding and absorbing of a complex academic repertoire by an unprepared audience. Biedermeier traits characteristic of different national and religious traditions are also analyzed and presented.

Conclusions: the Biedermeier as a specific phenomenon of musical culture, a kind of connecting musical "link" between elite art and "mass consumer" of art, creates certain pedagogical prerequisites for raising interest in various social strata of the society for the complex repertoire of classical music. Such an approach in understanding the idea of the Biedermeier, including the musical one, will prove to be essential in the revival of the values of planetary human unity and state principles - by the forces of individual and personal efforts of citizens and creators of Ukraine and countries and nations territorially historically close to it, since technological and analytical achievements and spiritual and social transformations in the human society are derived from the indicated general idea of the Great - through the small.
\end{abstract}

Citation: Nataliia Chuprina. (2019) Phenomenon of the Biedermeier Piano Music in XIX Century. Science Review.9(26). doi: 10.31435/rsglobal_sr/30112019/6814

Copyright: (C) 2019 Nataliia Chuprina. This is an open-access article distributed under the terms of the Creative Commons Attribution License (CC BY). The use, distribution or reproduction in other forums is permitted, provided the original author(s) or licensor are credited and that the original publication in this journal is cited, in accordance with accepted academic practice. No use, distribution or reproduction is permitted which does not comply with these terms.

Relevance of the reviewed topic. The idea of the Biedermeier was formed at the beginning of XIX cent., holding the most characteristic features of understanding of the world and worldview of the era of Restoration inside it, summarized by F. P. Fedorov at the time: "The era of Great metaphysic, great aspiration to the super-real, to other-being, if not yet completed, is going through its last time. Europe aspires to the history, to everyday life, to utilitarian values, to the pleasure in a small world, family, home; the great turmoil of the late XVIII - early XIX centuries gives ride to the longing for peace, for idyll; tyrants, heroes Fausts, Manfreds, Napoleons, obsessed with the longing for the beautiful Kreislers - are fading in the past; the function of demiurge are acquired by Ivans Petriviches Belkins; Goethe summarize the metaphysical era 
in the second part of "Faust", but creates the idyllic world of Philemon and Bavkid..." [quot. on: 2, 165]. Dealing with the designated era in its classical displays, the Biedermeier typology at the same time regained its actual sense in 2000s in the aspect of categorical "exaggerating" of symbolist attitudes to neo-symbolism at the turn of the millennium [see by Markova: 8], since it is early Romanticism and Biedermeier that are considered in the temporary literature as the main source of the designated style formations [5, 36]. The German source of Biedermeier aesthetics is obvious, although its reactivity to the early Christian cultural stratum, including the Russian Orthodox tradition, can also be traced initially [9, 147-149]. The accepting of the concept of Biedermeier as the art of Restoration points to the supernational dimensions of its principles, which is emphasized in the modern developments of this problem [see: 11, 12, 10 etc.]. Accordingly, the relevance of the topic is due to the modern awareness of the values of the "pronarrative" (by S. Lysuk's terminology [7]) layer of art of "small forms", loaded with the semantic density of musical messages of an ideal supper-existence order. The latter is determined by the revival of the religious outlook as the coexisting with scientific-philosophic worldview (R. Bart, G. Gadamer, V. Martynov etc.). The Organological activity transforming the tradition of the construction of electro-pianos is also obvious, in which the mechanisms of sound extraction deliberately combines the indicators of the piano and the clavier-organ expressive capabilities of this instrument. Thus, the halo of the only possible refraction of the expressive potential of this instrument is removed from the piano orchestrality, resurrecting the flavor of "light" piano of the era of Restoration and idealized "domesticaty" of their timbre quality.

Object of review - comprehension of the interethnic meaning of the Biedermeier as a Restoration art, consideration of projections of this phenomenon on piano music of XIX century.

Subject of review - Biedermeier's potential as a musical direction, opening up special pedagogical conditions for fostering an understanding of academic music among the non-professional community.

The statement of the main material. The acknowledgement of the Biedermeier as an autonomous historical-style display gave the opportunity of correlating the idea of the latter in the "homogeneous", according to O. Spengler [13], likeness to other cultural "organisms" with the wellknown "scheme", formulated as "origin - development - elimination". The last of these three phases "elimination" - does not contain a fatal assimilation to the final phase of a human`s physical existence as a person: the ideal principle of cultural being creates "post-glow" of creative style discovery, the inertia of which in one form of another creates an indestructible persistence in the subsequent expand of art and culture in general. As applied to the Biedermeier, one can see the homologous likeness of the stages of its formation as a genesis, realization-release, and final advance into the structure of other qualities. The aforesaid is determined by the fact of time of classics of any direction in art being determined by the intensity and concentration of its manifestation and, accordingly, by lower degree of detection of its specificity during "non-classical" stages of pre- and post- structural-semantic formations.

Biedermeier, as it was mentioned above, is a brainchild of the Restoration, its pronounced tone, inheriting from the background of concentration and tenderness the sensitive style of Rococo, which refracts the spiritual ecstasy of the early Christian religion, submitted to the Good Expectation in its abstracting from all the arts of prosaic beingness, to a large extent. The German genesis of this direction adopted in literature as its basic characteristic, which is determined by its very name term. The essence of German contribution to the time of manifestation of the Biedermeier classics and "post-style" detention of the latter is determined by the volume, for instance, of the creativity of R. Wagner, whose late romantic palette, according to German researchers, has also contained postBiedermeier traits. However, an aging of the given style quality conjugated not only with the German world, as well as that phase which is designated as "post-glow" of this style-direction.

The difference between pre- and post-Biedermeier style layers, along with highlighting of classics of Biedermeier in the first half of XIX cent., has the direct analogies with Romanticism, in which we can also designate some pre- and post-romantic style traits, apart from the developed artistic "physicality" of many-sized, multiple, multinational and, alongside, one in musical and artistic subjectivity of the expression of Romanticism. Pre- and post-symbolism are equally romantic in modern studies [see: 5, 28-42], while stating temporarily and territorially localized classics of this direction in French it in the late XIX - early XX cent.

The historical companionship Biedermeier and Romanticism forms a support of the given procedural review, as the other directions are much more rigidly attached to the national art structures that generate them (classicism, impressionism - France, expressionism - the German world etc.). The multinational manifestation of romanticism is largely due to its subjective nature, which is not so 
unambiguously found in the Biedermeier, inclined to a certain non-personalism. Nevertheless, the research, the results of which are summarized in the framework of this article, testifies to a rather flexible detection of the Biedermeier in multinational conditions, moreover, with a tendency to confront German proper - and non-German forms of the given direction.

In the role of a peculiar watershed in this process of distinguishing, on the one hand, appears the social factor (the burger spirit - German Biedermeier, the noble-salon - in a non-German cultural and historical area). On the other hand - the organological: the piano as a "substitute for the orchestra" and its analogue constitute one of the aspects of the German national idea, while in other countries this kind of expressive setting was pushed back by a pinch-funky refraction of the piano playing, which, ultimately, was determined in the art: in the first case, the theatricality of the German - Protestant image of the world is demonstrative< while tenderly enthusiastic tone of the representation of national consciousness in the commitment of the Ecumenical Church creates fundamentally different semantic dispositions. In this context the Biedermeier acts as a kind of "conductor" of academic musical art to the demands of the population, and to the understanding and introducing various social groups to the academic repertoire.

The analysis showed that the genesis of the Biedermeier at the "embryonic" stage of its development is evident in the second half of XVIII cent. at the crossroads of the stylistic qualities of Rococo and sentimentalism, which gave rise to the specific of Italian clavier/piano art, which fundamentally did not accept the German "piano orchestralty" that that had already formed at that time. The stated is obvious in the creativity of M. Clementi who historically appeared to be an educator of such a "Biedermeier classic" as J. Field. At the same time, the Italiat specificity of pianism, concentrated in $\mathrm{m}$. Clementi's piano legacy, alien to "German symphony", in century found a new sound in the works by K. Debussy, who blamed the works of L. Beethoven for their orchestrality. The depth of M. Clementi s position in the testament of clavier detection of piano style is comparable to the performance of the pre-symbolism of W. Blake in parallel to M. Clementi from 1780s to 1790. Such a time parallel between pre-Biedermeier and pre-symbolism is significant: it is precisely in the art of symbolism that the distinct manifestations of the Biedermeier covenants are recognizable, including in the deep interest in the exquisite simplicity of the artistic salon.

The completeness of the detection of Biedermeier in the period of 1810s-1830s under the auspices of the ideas of the Restoration is supplemented with a "neorococo" style "surge" during which the song and piano miniatures were filled with a connection between the "gallant" (in the etymological sense - fixing the manifestation of mercy) aria, while the "light' piano tone of the expression was detected in the "diamond" style, in the "pearl" technique of finger fluency, which developed in abundance the rhetoric of capturing the affect of joy and glorification.

The Biedermeier classic, capturing in its entirety the idea of the Restoration as an idyllic Reconciliation of multidirectional aspirations and a good Expectation of a revival of harmony between international and domestic relations through the harmoniousness of the family union in its broadest sense, gravitated to two expressive materializations: the song-romance vocals and the piano technique of "easy" finger play, correlated with the construction of "light piano". J. Field, whose Anglo-Irish origin of talent, genetically related to the French area, as well as the Slavic aspiration of the cultural roots of the nation he represents, has collectively determined the multinational advancement of the principles of his art in addition to the German school.

A common feature of Slavic quality, represented in this case by Polish and Russian schools, and the French Biedermeier, imprinted by the work of M. Szymanowska, personifying the Polish, but partly the Russian school, as well as J. Field, equally presenting the English, French and Russian traditions, is the accent salon component. This kind of genre and semantic inclination is due to the historical and social realities of European culture in the first half of the 19th century, which marked the significance of the contribution of aristocratic circles to the construction of the art of Restoration, in contrast to the German burgher-based social status of its participants Biedermeier.

As for the specifics of the Polish contribution, the most significant in it is the significance of the national-national element (evident in the broad appeal to the genre typologies of Mazurka and polonaise), while French Biedermeier was tuned to Celtic provincialism in the plot-programmatic refraction. In Russian Biedermeier, along with substantial attention to national specifics, there is a concentration on deliberate Europeanism and "Moscow provincialism" of expression at the same time. It should be noted that the latter quality is also a feature of the Russian pictorial Biedermeier, presented in the work of V. A. Tropinin. 
Among the distinguished national varieties of the phenomenon under consideration, we also single out the peculiarity of the Italian Biedermeier, laid down by the pre-Biedermeier activity of $\mathrm{M}$. Clementi and implemented by the Biedermeier position of J. Rossini, whose piano music was clearly dissociated from the Beethoven - post-Beethoven German piano orchestrality. Thus, J. Rossini demonstrated the characteristic for Risorgimento delimitation of the Italian image of musical thought from German symphony. This idea remained valid until the "late" J. Verdi, that is, until the 1870s, when the tendency of the mutual "sprouting" of the German and Italian musical picture of the world was again revealed. At a new stage, the interaction of the indicated national musical ideas is found in the activities of F. Busoni, E. Wolf-Ferrari [1, 836-837], and then in the activities of representatives of the modernist avant-garde of the twentieth century.

The indicated national separation of Biedermeier's heritage is also clearly visible in the postBiedermeier art space, in which the national "sign" is directly associated with vast experience of nationalfolkloristic affirmation in composer creativity, as well as with the intensity of the manifestation of prosymbolistic qualities. In French post-Biedermeier art, clearly depicted in the works of C. Debussy, dominant impressionism-symbolism is dominated, complemented by a connection with the salon of an artistic type, while "folk" features are presented here mainly in small forms of children's music.

In the Polish post-Biedermeier stratum, represented in this case by Z. Noskovsky and I. Paderevsky, the national component is extremely distinguished and, at the same time, contrasted with romantic Chopinism in its focus on the folk sources of South Polish art. In the Russian postBiedermeier wave, captured in the piano legacy of V. Rebikov, who represented the Moscow school, and also, due to the long period of work in Odessa, which entered the music of Ukraine, with a demonstrative impressionist and partly symbolist trend, emphasis is placed on the romantic Chopinist component. This aspect clearly combines the position of V. Rebikov with the stylistic preferences of his generation, represented by the names of A. Lyadov, A. Scriabin, S. Rachmaninov and others.

Is should be noted that the line of Chopinism is found both in the composer's and pianoperforming works of V. Rebikov. If in pre-Biedermeier art the basic role, as a reference to High in small forms, was played by the indicators of Baroque classicism and Rococo, then in Biedermeier's classics there is no direct reference to Rococo, but its "spirit" is preserved - as a complicity in the physical lightness of sound and as a reproduction various forms of Christian-religious singing through clavier "grace", correlated with Byzantine figurativeness in the Rococo melismatics and rhetorical passive identification in the piano nocturnes of J. Field.

This article does not specifically emphasize the manifestations of the German Biedermeier in distinguishing between his pre-, post-stages and classical expression, since such studies $[14,9,10$, etc.] quite clearly indicated the corresponding periods of existence of this direction.

The pedagogical aspect of the Biedermeier style may be its recognition as a kind of "creative laboratory", in which, regardless of the level of professional training, there is an opportunity to comprehend the "high idea" through small forms. Such "accessibility" of the presentation of musical material provides an opportunity to study various genre trends, which contributes to the mastery of the artist's palette of musical expressiveness in all its diversity.

On the basis of genre versatility, the process of cognition, awareness and embodiment of the dash and metro-rhythmic features of a work takes place with the aim of conveying a creative idea. The Biedermeier style, with its main idea of embodying "the great in the small," is fertile ground for mastering the pedagogical repertoire. Based on the foregoing, it can be argued that the features of the stated style are an integral part of the learning process among non-professional performers or performers with poor preparation, namely, piano possession. Given this specificity of performance, the teacher approaches the choice of a repertoire, starting with C. Czerny's instructive studies (for developing the technical base), through Kulau sonatas to Clementi sonatas, as well as J. Field's nocturnes (classic Biedermeier), up to the works of M. Shimanovskaya, Z. Noskovsky, I. Paderevsky and V. Rebikov (in their anticipation of the romantic style).

Thus, the student, within the framework of one style, has the opportunity to delve deeper and know a huge layer of style trends, their features and interactions in the multi-layer "texture" of 19th century piano art.

So, let us define the main stages of formation, the heyday of Biedermeier in piano music and its subsequent existence in the context of European culture at the turn of the 19th-20th centuries: preBiedermeier - 1760s - 1810s. with concentration in England-Britain and the work of its representatives (M. Clementi - J. Field) and in coexistence with early romanticism; Biedermeier classic period - 1815 
- 1848 with the leadership in it of the German cultural idea with the simultaneous substantial contribution of the Slavic countries (Poland, Russia), as well as Italy and France; post-Biedermeier 1850s - 1870s, - accompanying the pre-symbolism of the Pre-Raphaelites and S. Baudelaire, as well as organically "merging" into the symbolist "simplicity" of the salon culture.

The adoption of the specified chronology of the manifestation of Biedermeier aesthetics in European art of the second half of the XVIII - XIX centuries. allows you to evaluate the artistic "polyphony" of styles-directions of the called "romantic" century, in which the volitional-expansive aesthetics of Baroque-Classicism-Romanticism-Realism/Verism was only one of the main lines of the artistic-style "polyphony" of Europe. The role of the second line was played by the totality of Rococosentimentalism-Biedermeier-symbolism /impressionism, which demonstrated a contemplatively idealized perspective on the worldview, complementing the restrained aestheticism of its artistic positions with the artistic and dramatic aspect of creativity in line with the first of the aforementioned series of continuity of styles. A special page in these assimilation of rational interactions in the Biedermeier manifestation is occupied by the Ukrainian manifestation, composing a special and originally developed topic by a number of authors $[6,3]$.

By the will of historical circumstances, the neosymbolism of the beginning of the XXI century revived the idea of a meek "quiet light" of Biedermeier culture, in which hopes for harmony between the world and the state were refracted through the harmonization of individual souls of connoisseurs of aesthetics / ethics in this direction. "This music is closed in itself - not for concerts, but in order to live alone under it everyday. It is like everyday life itself, but not from the surface on which you are mostly forced to stay for a hundred reasons, but comes from beneath this surface, from where you glance at a moment of tranquility from time to time, discovering the true course of life within yourself ..." [4].

Conclusions. The Biedermeier as a specific phenomenon of musical culture, a kind of connecting musical "link" between elite art and "mass consumer" of art, creates certain pedagogical prerequisites for raising interest in various social strata of the society for the complex repertoire of classical music. A similar approach to understanding the idea of Biedermeier, including the musical one, proves to be essential in the revival of the values of planetary human unity and state principles by the forces of individual and personal efforts of citizens and creators of Ukraine and the countries and peoples territorially historically close to it, since technological and analytical achievements and spiritual and social transformations in the human community are derived from the indicated general idea of the Great - through the small.

\section{REFERENCES}

1. Vol'f-Ferrari E. (1973). Muzykal'naya entsiklopediya, 1, 836-837 [in Russian].

2. Daykhin T. L. (2014). Biedermeier - break through time and space. Ural'skiy filologicheskiy vestnik. Seriya: Russkaya klassika: Dinamika khudozhestvennykh sistem, 3, 165-173 [in Russian].

3. Zhmurkevich Z. S. (2007). Galician music Biedermeier (based on piano works of printed music collections of Lviv XIX c.). Extended abstract of candidate's thesis. Lviv: Lviv National Music Academy. Lysenko [in Ukrainian].

4. (From the other letters) (2016). Retrived from http://asheludyakov.com/ru

5. Kassu ZH. (1999). Encyclopedia of symbolism: painting, drawing and sculpture. Literature. Music. Moskva: Respublika [in Russian].

6. Kozarenko O. (2009). Biedermeier style model as relevant Ukrainian music. Muzychne mystetstvo i kul'tura. Naukovyy visnyk ODMA imeni A. V. Nezhdanovoyi, 10, 152-157 [in Ukrainian].

7. Lysyuk S. R. (2011). Narrative approach in characteristic style and stylistic features piano performance. Extended abstract of candidate's thesis. Odessa: National Music Academy named A. V. Nezhdanova [in Ukrainian].

8. Markova Ye. N. (2006). Neo neosimvolizm Eurocentrism and the beginning of the XXI century. Neo Yevropotsentrizm: Muzykal'naya kul'tura na rubezhe tysyacheletiy, 1, 76-115 [in Ukrainian].

9. Muravs'ka O. (2010). Essays on the history of foreign music culture. Odessa: Drukars'kyy dim [in Ukrainian].

10. Oleynikova O. V. (2010). Biedermeier and its manifestation in vocal music XIX-XX centuries. Extended abstract of candidate's thesis. Odessa: National Music Academy named A. V. Nezhdanova [in Ukrainian].

11. Sarab'yanov D. (1998) Biedermeier. Style without names and masterpieces. Pinakoteka, 4, 4-11 [in Russian].

12. Sarab'yanov D. (1980). Artists range Venetsianov and German Biedermeier. Russkaya zhivopis' XIX veka sredi yevropeyskikh shkol. Moskva: Sovetskiy khudozhnik [in Russian]

13. Shpengler Osvald. (2016). Retrived from viket.ru/enc/Шпенглер

14. Heussler H. (1959). Das Biedermeier in der Musik. Die Musikforschung. XII Jahrgang. Kassel, Basel: Barenreiter Verlag [in Germany] 